1 Assessing the role of the "estuarine filter" for emerging contaminants:

2

2

3

4

\author{
pharmaceuticals, perfluoroalkyl compounds and plasticisers in
}

\author{
sediment cores from two contrasting systems in the southern U.K.
}

Omar Celis-Hernandez ${ }^{1,2,3}$, Andrew B. Cundy ${ }^{3 *}$, lan W. Croudace ${ }^{3}$, Raymond D. Ward ${ }^{4,5}$, Rosa

\title{
Busquets $^{6}$ and John L. Wilkinson? ${ }^{7}$
}

${ }^{1}$ Instituto de Ciencias del Mar y Limnología, Universidad Nacional Autónoma de México, Estación el Carmen, Campeche, C.P. 24157, Ciudad del Carmen, México.

${ }^{2}$ Dirección de Cátedras CONACYT. Av. Insurgentes Sur 1582, Alcaldía Benito Juárez, C.P. 03940, Ciudad de México.

${ }^{3}$ School of Ocean and Earth Science, University of Southampton, National Oceanography Centre (Southampton), European Way, Southampton, SO14 3ZH, U.K.

${ }^{4}$ Centre for Aquatic Environments, University of Brighton, Cockcroft Building, Moulsecoomb, Brighton BN2 4GJ, U.K.

${ }^{5}$ Institute of Agriculture and Environmental Sciences, Estonian University of Life Sciences, Kreutzwaldi 5, EE-51014 Tartu, Estonia

${ }^{6}$ Kingston University London, Faculty of Science, Engineering and Computing, Kingston Upon Thames KT1 2EE, U.K.

${ }^{7}$ Department of Environment and Geography, University of York, Heslington, York, YO10 5NG, U.K.

*Corresponding author, A.Cundy@soton.ac.uk 
27 The environmental occurrence, fate and ecotoxicity of emerging contaminants (ECs) has been the subject of increasing research, policy and public concern over the past two decades. While a

29 wide range of publications have examined the environmental persistence and sediment/soil 30 interactions of ECs following their discharge into aquatic environments, the extent to which ECs

31 are sequestered in estuarine sediments, and the impact of this on their environmental

32 persistence and supply to the ocean, in comparison remains unclear. This Article examines the

33 environmental concentrations of seven, relatively water-soluble and environmentally mobile,

34 ECs (including pharmaceuticals, perfluoroalkyl compounds, and plasticisers) in dated intertidal

35 saltmarsh cores from two contrasting estuarine sites in the southern U.K. (one heavily

36 urbanised/industrial, the other non-urbanised). Mean sediment EC concentrations are similar in

37 both estuarine systems (in the range 0.1 (acetaminophen) to 17 (4-hydroxyacetophenone) ng/g

38 dry weight). Despite their variable reported Log $K_{\text {ow }}$ values (from ca. 0.5 to > 7), the ECs are all

39 apparently mobile in the marsh systems studied, and where subsurface concentration maxima

40 are present these most likely relate to local flushing or diffusive processes and cannot be clearly

41 linked to likely input trends or changes in sediment geochemistry (including sedimentary

42 organic carbon content). The "estuarine filter" here, at least with respect to intertidal saltmarsh

43 sediments, shows reduced potential to sequester the seven ECs examined and mediate their 44 supply to coastal and shelf environments. 
46 Keywords: Emerging contaminants; saltmarsh; pharmaceuticals; perfluorinated compounds;

47 plasticisers; estuary. 


\section{Introduction}

50 The environmental occurrence, fate and ecotoxicity of emerging contaminants (ECs - commonly

51 defined as any compound, both synthetic and natural, in the environment whose presence is

52 not routinely monitored and shows the potential to cause ecological disruption (Smital, 2008)),

53 has been the subject of increasing research, policy and public concern over the past two

54 decades (e.g. Kolpin et al., 2002; Petrie et al., 2015; Wilkinson et al., 2015; Costa et al., 2019;

55 Gaston et al., 2019). Emerging contaminants include a wide range of pharmaceutical residues

56 (inter alia illicit drug metabolites), perfluoroalkyl compounds, plasticisers, nanomaterials and

57 microplastics derived from various sources, notably waste water treatment works, but also

58 from non-point sources such as run-off from streets and agricultural land (Richardson and

59 Ternes, 2018). Despite their presence at typically $\mu \mathrm{g} / \mathrm{L}$ or sub- $\mu \mathrm{g} / \mathrm{L}$ concentrations, residues of

60 several ECs have been observed to cause biological disruption/dysfunction, and generational

61 effects, in exposed organisms via a number of mechanisms including endocrine dysfunction

62 (Chen et al., 2018; Thomas et al., 2018).

63 A wide range of publications have examined the environmental persistence, sediment/soil

64 interactions and breakdown processes of ECs once discharged into aquatic environments, with

65 several papers noting the interaction and burial / persistence of ECs in river bed and other

66 sediments. Indeed, Thiebault et al. (2017) note the preservation of general trends in historical

67 loading (over the last 50 years) of eight pharmaceutical products in dated sediment cores from

68 urban sediment in Orleans, France. However, and despite the expected "salting out" effects 
observed for a range organic contaminants with increases in salinity (Turner, 2003; Munoz et al., 2017), this apparent long-term sequestration and historical preservation may be less

71 effective in higher salinity settings such as estuaries (e.g. Labadie et al., 2007; Zhao et al., 2015).

72 This is important as estuaries, and estuarine sediments, play an important role in mediating the

73 transfer of a range of organic and inorganic contaminants to the ocean through the action of

74 the so-called "estuarine filter", where elements and compounds are sequestered in fine

75 intertidal and subtidal sediments and thus prevented from directly entering marine

76 environments (Cundy and Croudace, 2017). While a number of authors have reported

77 sedimentary concentrations of various ECS in estuaries, the extent to which ECs are removed

78 and sequestered in estuarine sediments, and the impact of this on their degradation and

79 environmental persistence (particularly across the strong Eh/pH gradients observed in

80 subsurface estuarine sediments) remains relatively unclear. Here, we adapt a recently

81 developed analytical method (Wilkinson et al., 2016) using high performance liquid

82 chromatography (HPLC) tandem mass spectrometry (MS/MS) to simultaneously examine the

83 environmental concentrations of seven ECs (which have potential medium- to long-range

84 mobility through fluvial to marine systems due to their relative hydrophilicity, including

85 pharmaceuticals, perfluoroalkyl compounds, and plasticisers) in dated intertidal saltmarsh cores

86 from two contrasting estuarine sites in the southern U.K. We examine the downcore

87 distribution of these ECs to determine (a) to what extent they persist in the sediment column,

88 (b) whether downcore trends in EC concentration can be correlated with local industrial and

89 urban activity, and (c) the potential role of these sediments, and the estuarine filter as a whole,

90 in mediating EC supply to the coastal and shelf environments. 


\subsection{Study area}

Sediment cores were collected in 2016 from the Hythe saltmarsh system (on the western side of Southampton Water, U.K.), and the southern Beaulieu river (Figure 1). Southampton Water is a $10 \mathrm{~km}$ long and $2 \mathrm{~km}$ wide estuary that is one of the largest estuarine systems in the southern UK (Quaresma et al., 2007). The rivers Test and Itchen are the main contributors of fresh water to the estuary, supplying approximately $1.54 \times 10^{6} \mathrm{~m}^{3}$ of fresh water per day (Hydes, 2000) and $2 \times 10^{4}$ tons of total suspended sediment per year (Velegrakis et al., 1999). The estuary hosts a range of coastal ecosystems such as saline lagoons, saltmarshes and mudflats that support a range of breeding and migratory birds, crabs and other organisms (JNCC, 2017). The head of the estuary is highly urbanized, with the city of Southampton (population 256,459 (2018 data, Southampton City Council, 2019), covering an area approximately $51.8 \mathrm{~km}^{2}$ ) and Southampton port (the second largest container terminal in the UK, which handles around 14 million tons of cargo each year). There is intensive industrial use of the western shore area with the large-scale Exxon Mobil oil refinery at Fawley and related industries that use the feedstock from the refinery. In contrast, the Beaulieu estuary is relatively undeveloped and lies in the New Forest National Park, an area of predominantly open heath and bog with little agriculture and very few urban areas (although it does receive sewage effluent discharges from 3 upstream continuous discharge WWTWs, with E. coli readings sufficiently high to historically close local clam fisheries (CEFAS, 2015).

The Hythe marsh is a Halimione portulacoides dominated marsh system, with patchy Spartina spp. and Puccinellia maritima, which is $1-2 \mathrm{~km}$ North West of the chemical industrial complex 
113 and Exxon Mobil oil refinery at Fawley. This marsh area has been shown previously to retain 114 relatively undisturbed (and laterally consistent) geochemical records of temporal contaminant 115 input to Southampton Water (e.g. Cundy and Croudace, 2017). The Beaulieu site was a similar 116 mixed Spartina spp. and Halimione portulacoides marsh, located 200m north of the Royal 117 Southampton Yacht Club. Previous work in the Beaulieu marsh systems has also demonstrated 118 that these marshes retain a relatively complete and consistent record of past contaminant 119 inputs into the Beaulieu estuary (Cundy and Croudace, 1996; Thomson et al., 2002). Both sites 120 cored are significantly below the main freshwater:seawater mixing zone in each estuarine 121 system, and show near fully-marine salinities. 


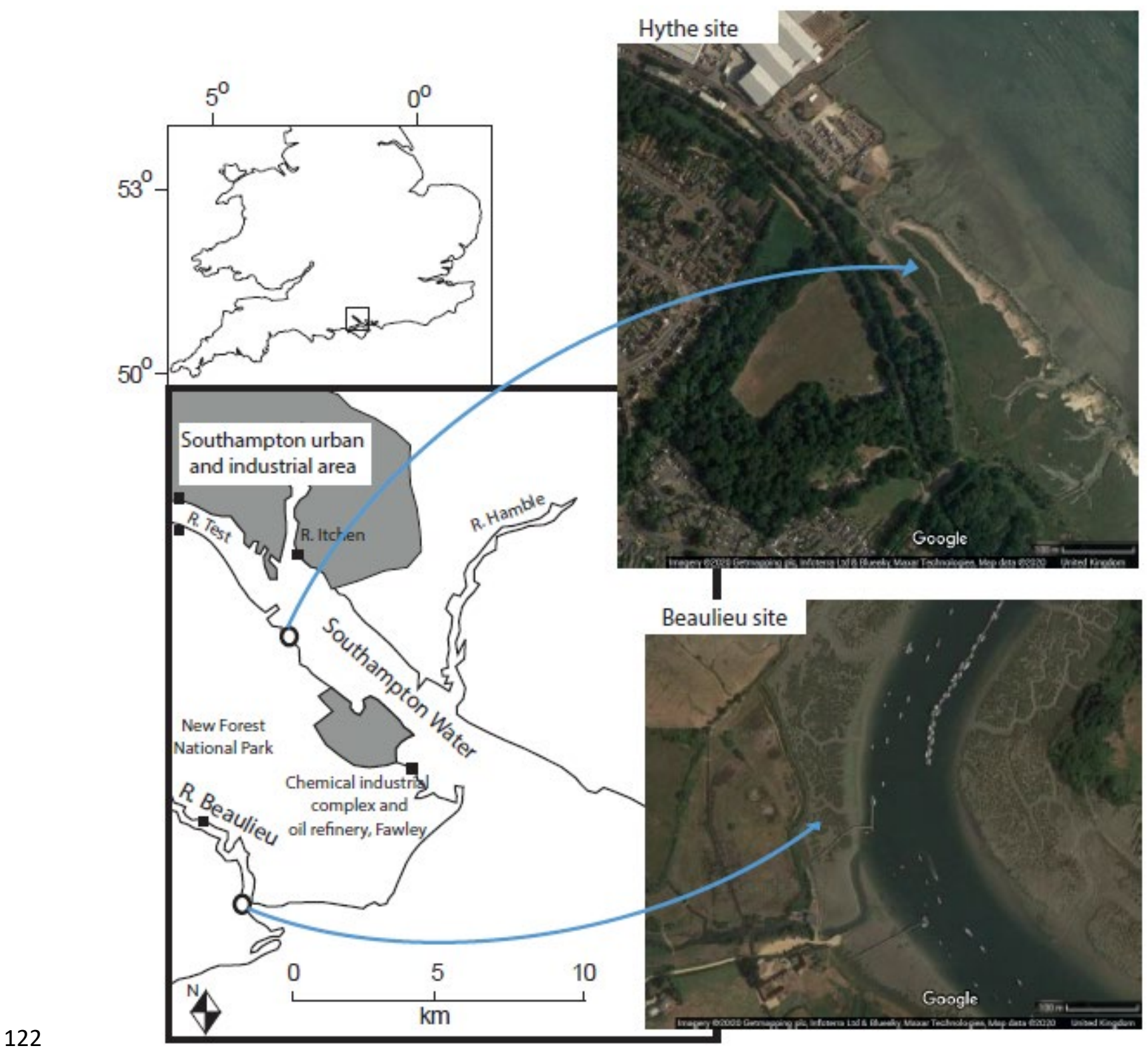

123 Figure 1. Study area: Southampton Water and the Beaulieu estuary, southern U.K. Aerial

124 photographic images show detail of marsh areas sampled. Filled squares show locations of

125 major wastewater treatment works (> 10,000 population equivalent) or site of smaller water

126 company continuous wastewater discharge (Beaulieu river). Aerial photographic imagery

127 Copyright 2020 Google. Map data Copyright 2020 Google. 


\subsection{Chemicals and materials}

130 Solvents used for the extraction and chromatographic separation of the study compounds were 131 of LC-MS grade (Honeywell Riedel-de Haën, Germany) and chemicals were of analytical quality 132 (purity >96\%) from Sigma-Aldrich (UK). The compounds selected for analysis, based on 133 preliminary screening and chosen to represent a range of ECs chemistries, groups and potential 134 sources (Table 1), and included the pharmaceutical acetaminophen; monomers bisphenol-S 135 (BPS), bisphenol-A (BPA) (and its biotransformation product 4'-hydroxyacetophenone (HAP)), 136 and the perfluoroalkyl (PFASs) compounds: PFOA, PFNA, and PFBS.

138 Stock solutions of each compound were prepared at $1000 \mathrm{mg} / \mathrm{L}$ in acetonitrile. Stock solutions 139 were further diluted to intermediate solutions containing a mixture of all compounds (25 and 5 $140 \mathrm{mg} / \mathrm{L}$ ) in acetonitrile, and further diluted in the same solvent to achieve the concentration 141 levels of $4 ; 20 ; 100 ; 250$; and $500 \mu \mathrm{g}$ BPA/L; $2 ; 10 ; 50 ; 125 ; 250$; and $500 \mu \mathrm{g}$ BPS and HAP/L and

$142 \quad 0.2 ; 1 ; 5 ; 13 ; 25 ; 50$ and $100 \mu \mathrm{g} / \mathrm{L}$ for the rest of the study compounds. Standards were stored at $143 \quad 4^{\circ} \mathrm{C}$ in a refrigerator until analysis. 
146 Table 1: List of compounds assessed, their pKa, log $\mathrm{K}_{\mathrm{ow}}$ and production/usage history.

\begin{tabular}{|c|c|c|c|c|}
\hline Compound & Compound type & pKa & Log $K_{\text {ow }}$ & History \\
\hline Acetaminophen & Pharmaceutical & $9.38^{a}$ & $0.46^{a}$ & $\begin{array}{l}\text { Pain reliever and fever reducer, } \\
\text { first discovered } 1866 \text {. Introduced } \\
\text { to the UK in } 1956 .\end{array}$ \\
\hline Bisphenol A (BPA) & $\begin{array}{l}\text { Crosslinker in } \\
\text { polymers and } \\
\text { thermal paper }\end{array}$ & $\begin{array}{l}9.6^{a} \\
9.44^{b}\end{array}$ & $\begin{array}{l}3.32^{a} \\
1.65^{b}\end{array}$ & $\begin{array}{l}\text { Cross-linker in polycarbonate } \\
\text { plastics and epoxy resins } \\
\text { production and additive in } \\
\text { polyvinyl chloride. Invented in } \\
1891, \text { first synthesis in 1905, } \\
\text { expanded use from 1930s (epoxy } \\
\text { resins) and 1950s (polycarbonate } \\
\text { plastics). }\end{array}$ \\
\hline $\begin{array}{l}\text { 4- } \\
\text { hydroxyacetophenone } \\
\text { (HAP) }\end{array}$ & $\begin{array}{l}\text { Metabolite and } \\
\text { degradation } \\
\text { product from } \\
\text { BPA }\end{array}$ & $\begin{array}{l}8.12^{\mathrm{a}} \\
10.43^{\mathrm{b}}\end{array}$ & $3.31^{b}$ & $\begin{array}{l}\text { Used in cosmetics and personal } \\
\text { care products, also metabolite } \\
\text { and biotransformation product } \\
\text { of BPA. }\end{array}$ \\
\hline Bisphenol S (BPS) & $\begin{array}{l}\text { Crosslinker in } \\
\text { polymers and } \\
\text { thermal paper }\end{array}$ & $\begin{array}{l}8.2^{a} \\
8.47^{b}\end{array}$ & $\begin{array}{l}1.65^{\mathrm{a}} \\
3.19^{\mathrm{b}}\end{array}$ & $\begin{array}{l}\text { Close analogue of Bisphenol A, } \\
\text { first manufactured in } 1869 \text { as a } \\
\text { dye. BPS has been used as a } \\
\text { recent substitute for BPA in an } \\
\text { increasing number of products. }\end{array}$ \\
\hline $\begin{array}{l}\text { Perfluorobutane } \\
\text { sulfonic acid (PFBS) }\end{array}$ & $\begin{array}{l}\text { Perfluoroalkyl } \\
\text { and } \\
\text { Polyfluoroalkyl } \\
\text { Substance (PFAS) }\end{array}$ &.$-3.31^{a}$ & $1.82^{c}$ & \multirow{3}{*}{$\begin{array}{l}\text { Surfactants used in various } \\
\text { commercial and industrial } \\
\text { applications since the 1940s. }\end{array}$} \\
\hline $\begin{array}{l}\text { Perfluorononanoic } \\
\text { acid (PFNA) }\end{array}$ & $\begin{array}{l}\text { Perfluoroalkyl } \\
\text { and } \\
\text { Polyfluoroalkyl } \\
\text { Substance (PFAS) }\end{array}$ & $\begin{array}{l}<1^{\text {a }} \\
\sim 0^{d}\end{array}$ & $\begin{array}{l}4.84- \\
7.27^{\mathrm{e}}\end{array}$ & \\
\hline $\begin{array}{l}\text { Perfluoroctanoic acid } \\
\text { (PFOA) }\end{array}$ & $\begin{array}{l}\text { Perfluoroalkyl } \\
\text { and } \\
\text { Polyfluoroalkyl } \\
\text { Substance (PFAS) }\end{array}$ & $\begin{array}{l}2.8^{\mathrm{a}}, \\
\sim 0^{\mathrm{d}}\end{array}$ & $\begin{array}{l}6.30^{a} \\
4.3^{f}\end{array}$ & \\
\hline
\end{tabular}

${ }^{a}$ Derived from PubChem database, National Library of Medicine, National Center for Biotechnology Information, USA. https://pubchem.ncbi.nlm.nih.gov/, accessed July 2020.

${ }^{b}$ Wang et al., 2002

c https://www.epa.gov/tsca-screening-tools, accessed July 2020.

d Goss, 2008

e Howard and Meylan, 1997

${ }^{\mathrm{f}}$ Arp et al., 2006 


\section{$157 \quad 2.3$ Sample preparation and extraction - ECs.}

158 Following collection, cores were split vertically, sub-divided into $1 \mathrm{~cm}$ depth increments and 159 freeze-dried. Dried sediment samples (3g) were extracted with hexane and acetone (1:1) using 160 microwave extraction (MARS 6 CEM microwave digester system, UK) following the EPA method 161 3546. For the determination of recovery rates in sediments from each site, and the 162 repeatability of the extraction protocol and LC-MS analysis (Supporting Information), sediment 163 samples (3g) were spiked with stock solution, containing a mixture of the study compounds to 164 concentrations of $0,50,100,200$, and $300 \mathrm{ng}$ contaminants/g sediment (in triplicate). Spiked 165 samples were left in the dark for 24 hours before extraction to allow (a) for solvent evaporation 166 and (b) for contaminant/sediment interaction. The slope between the amount of contaminant 167 added and the amount found, expressed in \%, was used to estimate recovery in the analysis 168 and correct results for incomplete extraction and the effect of the matrix on the MS signal of

169 the compounds. Enriched extracts obtained with microwave extraction were kept in 10 ml glass 170 vials and preconcentrated to $0.5 \mathrm{ml}$ with a gentle stream of nitrogen. The samples were then

171 brought to $1 \mathrm{ml}$ with methanol. Samples were analysed within 2 days and were kept in a 172 refrigerator $\left(4^{\circ} \mathrm{C}\right)$ until analysis. Extracts were filtered through Whatman GF/F-grade glass 173 microfiber filters (diameter $47 \mathrm{~mm}$, pore size $0.7 \mu \mathrm{m}$ ) from Fisher Scientific (Loughborough, 174 U.K.) just before analysis. Recovery rates ranged between 7 and 28\% (Table S1 - the relatively 175 low recoveries are a consequence of the limited clean-up of compounds extracted from the 176 sediments to ensure sub-LOD blank values - see further discussion in SI). 
$179 \quad 2.4$ Sample analysis - LC-MS.

180 The chromatographic separation of the study compounds was carried out using a $\mathrm{C}_{18}(150 \mathrm{~mm} \times$ $1812.1 \mathrm{~mm}$ ) analytical column with a particle size of $2.6 \mu \mathrm{m}$, protected with a Securityguard 182 ULTRA $^{\mathrm{TM}}$ UHPLC $\mathrm{C}_{18}(4.6 \mathrm{~mm} \times 2.1 \mathrm{~mm})$ guard column, both from Kinetex ${ }^{\circledast}$ (Phenomenex, 183 Macclesfield, U.K.). The separation was carried out with a 1260 Infinity LC (Agilent 184 Technologies, US). Optimal separation was achieved with a binary mobile phase at a flow-rate 185 of $0.2 \mathrm{ml} / \mathrm{min}$. The elution program was: $20-65 \%$ of acetonitrile in water $(\mathrm{v} / \mathrm{v}), 0-15 \mathrm{~min}$; and 186 return to the initial conditions in $5 \mathrm{~min}$; followed by 5 min equilibration. The injection volume 187 was $10 \mu \mathrm{l}$. The detection of the study compounds was carried out with a 6430 triple quadrupole 188 mass spectrometer from Agilent Technologies (US), equipped with electrospray (ESI) ionisation 189 operating in positive and negative mode depending on the analyte being eluted. Data 190 acquisition was performed in multiple reaction monitoring (MRM) mode using the protonated 191 molecular ion (for ESI + mode) and the deprotonated molecular ion (for ESI - mode) as 192 precursor ion and two product ions for the quantification and confirmation of the analytes (See 193 Table S2). Optimised ionisation source working parameters for study compounds were: 194 capillary voltage, $\pm 4 \mathrm{kV}$; nebulizer gas $15 \mathrm{psi}$; curtain gas, $11 \mathrm{~L} / \mathrm{min}$, gas temperature, $300^{\circ} \mathrm{C}$. 195 Collision energy, fragmentor and electron multiplier voltage were optimised for two transition 196 ions per target analyte and internal standard using electrospray ionisation (Table S2). The 197 acquisitions software was Mass Hunter version B.04.00. The analytical method has previously 198 been validated following ICH guidelines (ICH, 2005; Wilkinson et al., 2016). Limits of detection 
199 and limits of quantification for each of the target analytes are shown in Table S3. Quantification

200 uncertainties ranged between 13 and 24\% (Table S4).

201

202 Robust quality control measures were implemented throughout analysis. Before beginning each

203 analytical run, the chromatography column was equilibrated using 15 injections of LC-MS grade

204 water. Blanks, consisting of methanol, were injected after calibration standards and quality

205 controls to ensure that cross contamination in the system did not occur. Furthermore, both

206 quality controls and blanks were injected after every 5 environmental samples.

2.5 Sample analysis - radiometric dating, inorganic geochemistry, organic carbon and 209 granulometry.

210 Sediment cores were vertically sub-sampled at $2 \mathrm{~cm}$ depth increments, and freeze-dried 211 sediment samples counted for at least 16 hours on a Canberra well-type HPGe gamma-ray

212 spectrometer to determine the activities of ${ }^{137} \mathrm{Cs}$ and other gamma-emitting radionuclides.

213 Freeze-dried samples (as pressed pellets) were also analysed using a Philips Magix-Pro WD-XRF

214 fitted with a $4 \mathrm{~kW}$ Rh target X-ray tube, to determine geochemical composition. Radiometric 215 methods and XRF geochemical analysis methods are well established and reported in Croudace 216 et al., 2012. Organic carbon content was estimated using the loss on ignition method (LOI, at $217450^{\circ} \mathrm{C}$ for 24 hours), and a carbon conversion factor for saltmarsh soils (Craft et al., 1991). 218 Particle size distribution within sediment samples was determined using a Malvern Mastersizer 2192000 laser particle size analyser. One gram of homogenized sediment was mixed with $10 \mathrm{~mL}$ of 
220 dispersant solution of sodium hexametaphosphate. The mixture was stirred for 5 min in order

221 to deflocculate clay particles, after that time a small portion was taken for analysis.

\subsection{Statistical analysis}

224 A Pearson's correlation coefficient analysis was performed to evaluate the relationships 225 between the principal sedimentary variables (granulometry, organic carbon content), and the 226 organic micropollutants (BPA, BPS, acetaminophen, PFOA, PFNA, PFBS and HAP) for each site. 227 Following this, a Principal Component Analysis (PCA) was conducted using the sedimentary 228 characteristics (including bulk geochemical data) and pollution data for all samples from both 229 sites to evaluate trends in the data between sites. A cluster analysis (Q-mode) of the 230 environmental variables was also conducted using the sediment characteristics and organic 231 pollutant data for each site to evaluate the relationship between these factors on a site basis 232 and identify differences between the sites. Variables included the 34 core variables evaluated 233 (granulometry, concentrations of major and trace elements organic carbon and emerging 234 contaminants), which classified in a hierarchical structure using the complete linkage 1-Pearson $235 r$ method. All statistical analyses were conducted using Minitab 17 (PA, USA).

\section{Results and Discussion}

\subsection{Mean Emerging Contaminant (EC) concentrations.}

Mean EC concentrations observed in saltmarsh sediments are statistically similar at Hythe and 240 Beaulieu for all ECs examined (Table 2, p 0.05), ranging from 0.12 ng/g (acetaminophen), 
241 through 0.2-5.3 ng/g (perfluoroalkyl compounds) to 7.9-16.5 ng/g (BPA, BPS and HAP). All ECs

242 examined, with the exception of PFBS, were detected at concentrations significantly above 243 instrumental detection limits in $95 \%$ of samples analysed. For acetaminophen, concentrations 244 observed at both Hythe and Beaulieu (Table 2) are significantly lower ( $<10$ times) than values 245 reported for urban river sediments by Thiebault et al. (2017) and Wilkinson et al. (2018), and in 246 estuarine and coastal sediments in New Zealand and South Korea (Kim et al., 2014; Stewart et 247 al., 2014). For perfluoroalkyl compounds, a number of authors have noted the presence of very 248 low $(<10 \mathrm{ng} / \mathrm{g})$ concentrations of PFASs in estuarine and coastal sediments, near instrumental 249 detection limits or at non-detectable levels. For example, in a study of the north Bohai sea 250 region, China, Wang et al. (2011) recorded total concentrations of PFASs in sediments ranging 251 from < LOQ to $4.3 \mathrm{ng} / \mathrm{g} \mathrm{dw}$, with a mean of $0.62 \mathrm{ng} / \mathrm{g} \mathrm{dw}$. Perfluorooctane sulphonic acid (PFOS) 252 and PFOA were the dominant PFCs present. Mean sediment PFASs concentrations at Hythe and 253 Beaulieu show similar relative enrichment in PFOA compared to other PFASs, but overall 254 concentrations are significantly higher, and similar to concentrations at the upper range of 255 those previously reported for more contaminated estuarine or river systems (e.g. Kyoto, Japan 256 (Senthilkumar et al., 2007); Charleston, U.S.A. (White et al., 2015); sediments of three rivers in 257 greater London, U.K. (Wilkinson et al., 2018); and Beibu Gulf, China (Pan et al., 2020), Table 2). 258 Plasticizer concentrations (BPA, BPS, HAP) are broadly similar to those reported previously for 259 sediment cores from other coastal and marine areas, including the Pearl River Estuary (BPA up 260 to $12 \mathrm{ng} / \mathrm{g}$, Peng et al., 2007), Sea of Japan (BPA up to $10 \mathrm{ng} / \mathrm{g} \mathrm{dw}$, Hong and Shin, 2009) and 261 the southern Baltic Sea (BPA $<1-32 \mathrm{ng} / \mathrm{g}$, Lubecki and Kowalewska, 2019) (Table 2). In the 262 United Kingdom, Wilkinson et al. (2018) report mean concentrations of BPA, HAP and BPS 


\begin{tabular}{|c|c|c|c|}
\hline & \multicolumn{2}{|c|}{ Mean (SD) ng/g } & \multirow{2}{*}{$\begin{array}{l}\text { Previously reported data (other } \\
\text { locations) ng/g }\end{array}$} \\
\hline Compound & Hythe & Beaulieu & \\
\hline Acetaminophen & $0.12(0.02)$ & $0.13(0.03)$ & $\begin{array}{l}<2-35 \text { (Thiebault et al., 2017); <0.93- } \\
1.11 \text { (Wilkinson et al., 2018); 5.5-88.5 } \\
\text { (Kim et al., 2014); <50-145 (Stewart et } \\
\text { al., 2014). }\end{array}$ \\
\hline Bisphenol A (BPA) & $10.6(4.8)$ & $7.9(2.1)$ & $\begin{array}{l}\text { 1-12 (Peng et al., 2007); <LOQ-10 (Hong } \\
\text { and Shin, 2009); <1-32 (Lubecki and } \\
\text { Kowalewska, 2019); 4.62-14.69 } \\
\text { (Wilkinson et al., 2018). }\end{array}$ \\
\hline $\begin{array}{l}\text { 4-hydroxyacetophenone } \\
\text { (HAP) }\end{array}$ & $16.5(3.7)$ & $11.9(2.9)$ & <LOQ-5.65 (Wilkinson et al., 2018). \\
\hline Bisphenol S (BPS) & $8.0(1.4)$ & $7.94(2.2)$ & <LOQ-1.4 (Wilkinson et al., 2018). \\
\hline $\begin{array}{l}\text { Perfluorobutane sulfonate } \\
\text { (PFBS) }\end{array}$ & $0.2(0.04)$ & $0.2(0.06)$ & $<1.13-10.7$ (Wilkinson et al., 2018). \\
\hline $\begin{array}{l}\text { Perfluorononanoic acid } \\
\text { (PFNA) }\end{array}$ & $3.6(1.3)$ & $4.1(0.7)$ & $<0.75-78.6$ (Wilkinson et al., 2018). \\
\hline $\begin{array}{l}\text { Perfluoroctanoic acid } \\
\text { (PFOA) }\end{array}$ & $5.3(1.2)$ & $4.9(1.3)$ & $\begin{array}{l}<\text { LOQ-0.54 (Wang et al., 2011); 1.3-3.9 } \\
\text { (Senthilkumar et al., 2007); 0.02-2.52 } \\
\text { (White et al., 2015); <1.13-15.4 } \\
\text { (Wilkinson et al., 2018); <0.01-0.25 (Pan } \\
\text { et al., 2020). }\end{array}$ \\
\hline
\end{tabular}
sediment respectively in three freshwater rivers in greater London. Unlike in the Wilkinson et al. (2018) study of urban freshwater rivers, however, concentrations of the biotransformation product 4'-hydroxyacetophenone were generally higher than those of its parent BPA in the estuarine systems studied here (discussed further below).

Table 2: Mean concentrations of each analyte at Hythe and Beaulieu saltmarsh sites. Previously reported data for other locations are also shown (see text for discussion). 
273 The similar mean concentrations ( $p$ 0.05) found between the Hythe and Beaulieu cores for all 274 seven ECs examined indicates a relative ubiquity of these ECs in estuarine waters on the central 275 southern UK coast, which are readily measurable even in less industrialised and urbanised 276 settings (i.e. the Beaulieu estuary). The lack of clear enrichment in ECs in the heavily urbanised 277 and industrialised Southampton Water system over those found in the Beaulieu estuary is most 278 likely a consequence of (a) ECs input from a range of catchment sources, rather than a single 279 main or point source, and (b) mixing of these inputs on the tidal circulation prior to deposition 280 in the marsh systems. Pharmaceuticals and personal care products (e.g. acetaminophen) are 281 most likely to enter these estuaries via wastewater treatment plants and overflows from 282 combined sewers (Munro et al., 2019). There are five WWTPs directly discharging treated 283 effluent into the wider Southampton Water system with a combined population equivalence of 284 359,489 people (Portswood WWTP- p.e. 72657, Millbrook WWTP- p.e. 134433, Marchwood 285 WWTP- p.e. 74266, Woolston WWTP- p.e. 63622 and Ashlett Creek/Fawley WWTP- p.e. 14511). 286 In addition, there are at least five more discharging into rivers within $10 \mathrm{~km}$ of Southampton 287 Water. There are also at least nine combined sewage overflow points which will discharge 288 untreated sewage directly into Southampton Water during times of heavy rainfall. In the 289 Beaulieu River there are fewer wastewater sources, but there is a small WWTP just south of 290 Beaulieu village and 4-6 domestic properties or farms along the Beaulieu river with discharge 291 licences. There is also the Boldre WWTP which discharges into the Hatchet Stream which joins 292 with the Beaulieu River near the Southampton Yacht Club. These (and other) sources have been 293 linked with historical closure of local bivalve fisheries. In addition to inputs via WWTP discharge, 
PFASs are associated with areas of train traffic, airports, military and other training installations, port and boat activity and in storm runoff from built developments and roads (Zushi and Masunaga, 2009; Xiao et al., 2012; Ahrens et al., 2015; Yan et al., 2015; Anderson et al., 2016;

297 Wilkinson et al., 2016). While Southampton Water is a much more urbanised and industrialised system, both study estuaries share a range of these input sources, particularly boating activity and boatyards. Similarly, another important source of plastic degradation products and PFASs are plastic water pipes (Schaefer et al., 2006; Wilkinson et al., 2016). These sources are likely to provide a continual discharge to both estuarine systems, which are then mixed by tidal and other currents prior to deposition in the marsh systems.

\subsection{EC distribution with sediment depth, and retention of temporal trends in contaminant}

305 input.

306 The distribution of ECs with depth in each sediment core (Figure 2) is relatively irregular (Hythe-

307 BPA and HAP, and PFASs) or quasi-linear with a slight decline in concentration with depth

308 (remaining profiles). Acetaminophen shows a near-exponential decline in concentration with 309 depth in the Beaulieu marsh, from surface concentrations of $0.2-0.24 \mathrm{ng} / \mathrm{g} \mathrm{dw}$ to $\mathrm{ca} .0 .1 \mathrm{ng} / \mathrm{g}$ $310 \mathrm{dw}$ at $-20 \mathrm{~cm}$ depth, although this pattern is not replicated in the Hythe marsh core. At both 311 sites sampled, the seven ECs are present above respective LOD throughout the cored depth of $31235+\mathrm{cm}$. While slight inflections in the profiles frequently occur at similar depths, particularly 313 when comparing different PFASs, where clear subsurface concentration maxima are present 314 (e.g. Hythe core, for BPA, at $-26 \mathrm{~cm}$ depth) these do not correlate with peaks in other 
315 contaminants, or with subsurface maxima in organic carbon content (Figure 2, Table S5). As

316 noted above, concentrations of the biotransformation product HAP were generally higher than

317 those of BPA, shown by a ratio $>1$ at most sampled depths throughout the sediment cores

318 (Figure 3). Higher ratios of HAP to the BPA parent compound (HAP:BPA ratio) may indicate

319 greater transformation of BPA within WWTW, in-estuary or in-marsh degradation of BPA into

320 HAP, or additional HAP sources in these systems. There is no evidence however of consistent

321 changes of HAP:BPA with burial depth that may indicate increasing biotransformation of BPA

322 with burial time in the marsh. At Hythe, HAP:BPA ratios increase to $>4$ at $-15 \mathrm{~cm}$ depth, then

323 decrease to $<1$ due to the prominent subsurface maximum in BPA at $-26 \mathrm{~cm}$ depth. Although

324 similar HAP:BPA ratios were previously observed within the first $5 \mathrm{~cm}$ of sediment depth in

325 semi-rural stretches of the River Bourne in the U.K., those observed here were generally higher

326 than in sediment of small urban rivers (Wilkinson et al., 2018). This may be partially driven by

327 (a) diverse inputs of BPA into urban rivers (Osenbrück et al., 2007; Proctor et al., 2020)

328 increasing the amount of the parent compound relative to metabolites and (b) degradation of

329 BPA into HAP via sediment dwelling bacteria such as Pseudomonas putida (Eltoukhy et al.,

330 2020) and Sphingomonas sp. (Zhang et al., 2013). BPA to BPS ratios were generally close to 1 (or

331 less), with the exception of two samples at depth in the Hythe core - no consistent recent

332 decrease in this ratio was observed which might record the documented replacement of BPA

333 with BPS in industrial and commercial products. 

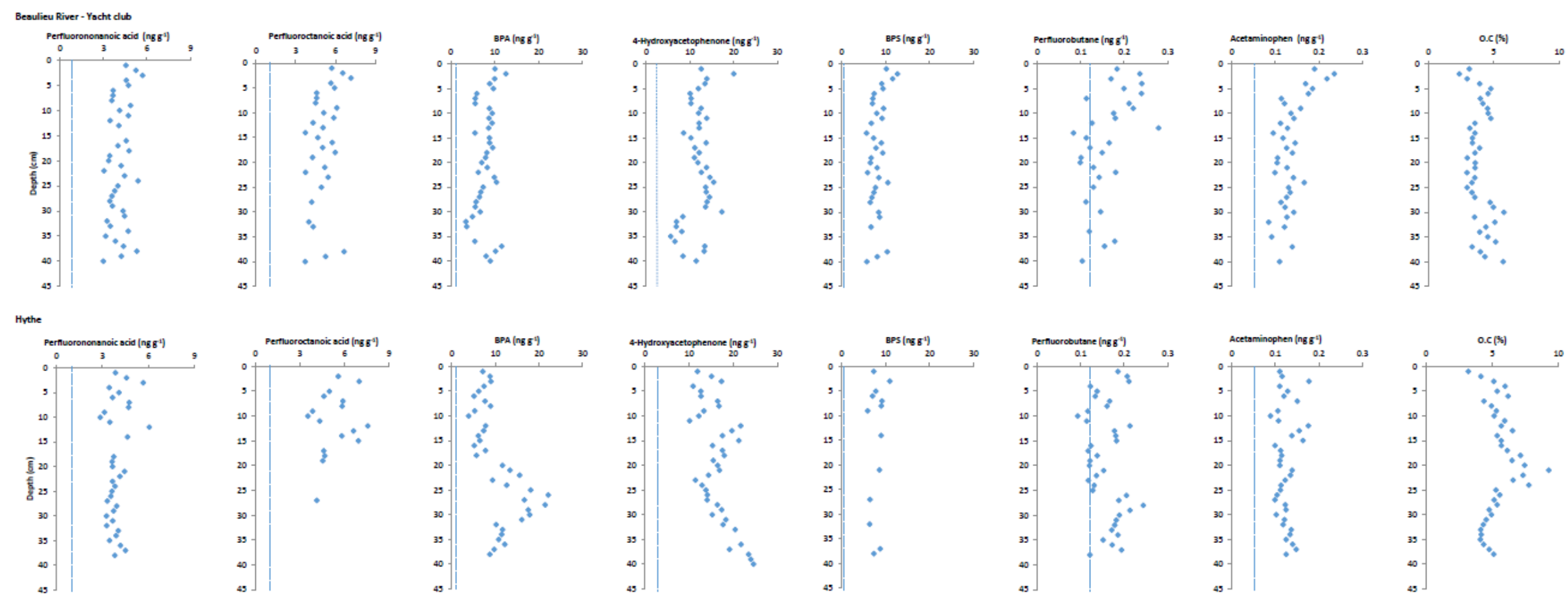

Figure 2: PFNA, PFOA, BPA, HAP, BPS, PFBS, acetaminophen and organic carbon (via LOI analysis) distribution with depth in Beaulieu (top) and

Hythe (bottom) saltmarsh cores. Profiles are arranged from high to low Kow (left to right). Dashed vertical line on selected graphs shows limit of

detection, determined at a signal-to-noise ratio of 3 from injection of spiked soil sample extracts (Table S3). 
Beaulieu River - Yacht club
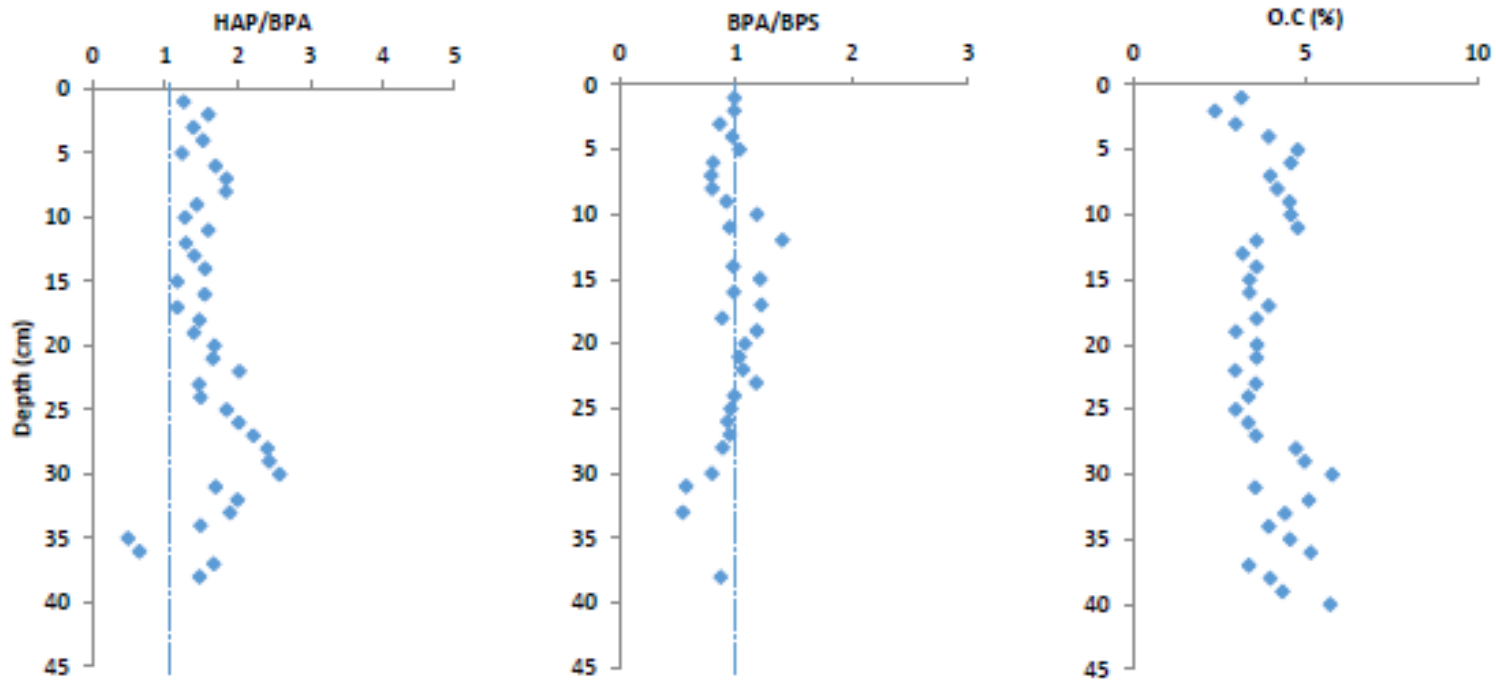

Hythe
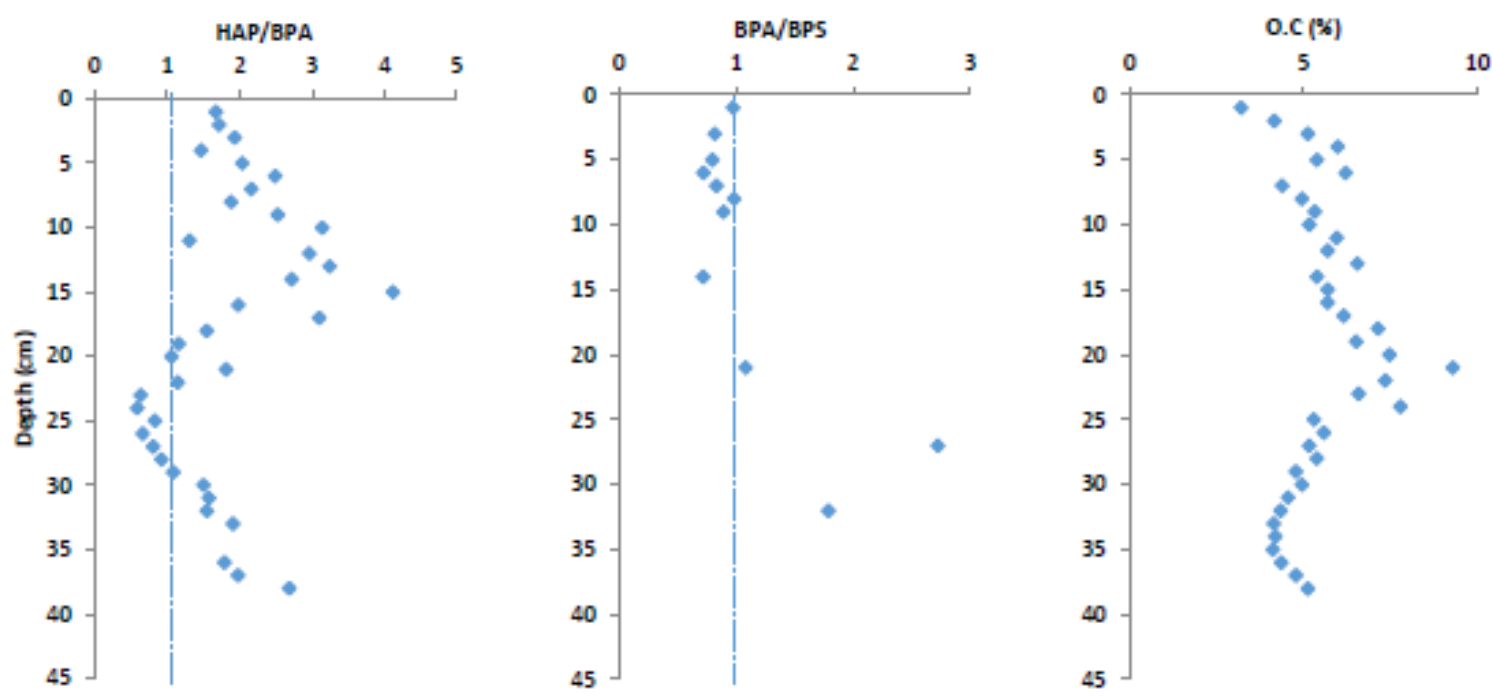

Figure 3: HAP/BPA and BPA/BPS ratios, and organic carbon (via LOI analysis), distribution

341 with depth in Beaulieu (top) and Hythe (bottom) saltmarsh cores. Dashed vertical line on

342 HAP/BPA and BPA/BPS graphs shows one to one ratio. 
The sediment cores examined were dated via ${ }^{137} \mathrm{Cs}$ dating, supported (at Hythe only) by

matching the vertical distribution of $\mathrm{Cu}$ in the sediment with the known discharge history of this heavy metal from the Fawley refinery (e.g. Cundy and Croudace, 2017). In both cores examined ${ }^{137} \mathrm{Cs}$ shows a prominent subsurface maximum at $-28 \mathrm{~cm}$ (Beaulieu) and $-23 \mathrm{~cm}$ (Hythe) (Figure 4), which in this region of the southern UK has been previously established to correspond to the 1963 fallout maximum from above ground nuclear weapons testing (Cundy and Croudace, 1996; Cundy et al., 1997; Cundy and Croudace, 2017). This provides a defined age marker in the sediment column, indicating a sediment accumulation rate of $c a$. $5 \mathrm{~mm} /$ year (Beaulieu) and ca. $4 \mathrm{~mm} /$ year (Hythe), in agreement with previously reported data for these and surrounding marsh systems (Cundy and Croudace, 1996; Cundy et al., 1997; Thomson et al., 2002; Cundy and Croudace, 2017). The broad subsurface maximum in $\mathrm{Cu}$ in the Hythe core between -20 and $-25 \mathrm{~cm}$ reflects increasing $\mathrm{Cu}$ discharges from the Fawley refinery prior to additional effluent control measures in 1970/71 (Cundy and Croudace, 2017), indicating a sediment accumulation rate of $4 \mathrm{~mm} / \mathrm{year}$ at Hythe, corroborating the ${ }^{137} \mathrm{Cs}$-derived rate (NB. Cu concentrations at Beaulieu conform with local geogenic background, Croudace and Cundy, 1995). Given these dates and sediment accumulation rates, it is clear that all ECs analysed are present at above-LOD concentrations in sediments deposited prior to 1960, and potentially (if constant sediment accumulation rates are assumed) in pre-1950 sediments. Some ECs therefore are found at depths which pre-date their widespread environmental introduction (e.g. acetaminophen, PFASs, Table 1), which indicates their diffusion or transport to deeper, older sediment core horizons, possibly driven by tidal flushing (i.e. horizontal and vertical percolation of incoming water associated with tidal inundation). This, and the lack of any consistent subsurface maxima or trends in concentration (or in EC ratios, e.g. BPA:BPS) that can be correlated with their 
increasing production and use, industrial development or urbanisation activities (e.g. known

368 timing of population increases, port and port traffic development, boating activity and

369 WWTW construction) highlights that these sediments do not contain a record of likely

370 historical contaminant loading each estuary, and do not record temporal trends in estuarine

371 EC inputs. This finding contrasts both with sediment core data for ECs in freshwater

372 (riverine) sediments presented by Thiebault et al., (2017) (and more recently by Mourier et

373 al., 2019), and with the recorded retention of trends in historical inputs of various heavy

374 metals, radionuclides and (for Southampton Water) hydrocarbon residues in the two

375 estuaries studied here (Little et al., 1988; Croudace and Cundy, 1995; Cundy and Croudace,

376 1996; Thomson et al., 2002; Cundy and Croudace, 2017). Similar mobility for estrone (E1)

377 has however been observed in clay-rich estuarine sediments in the Ouse estuary, UK

378 (Labadie et al., 2007), while Peng et al., (2007) found that nonylphenol was quantifiably

379 detected in sediments predating its widespread application (1940s) in the Pearl River estuary, suggesting the downward penetration of NP in the sediment column. 
Beaulieu River - Yacht club

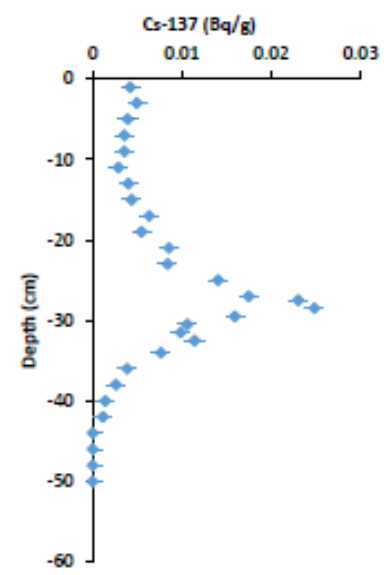

Hythe

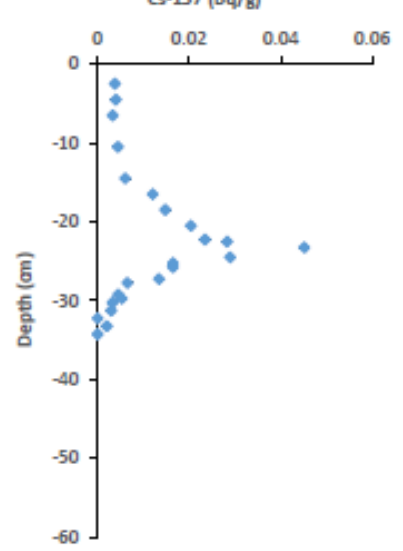

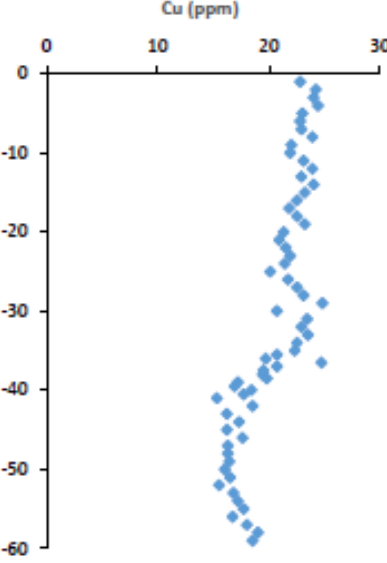
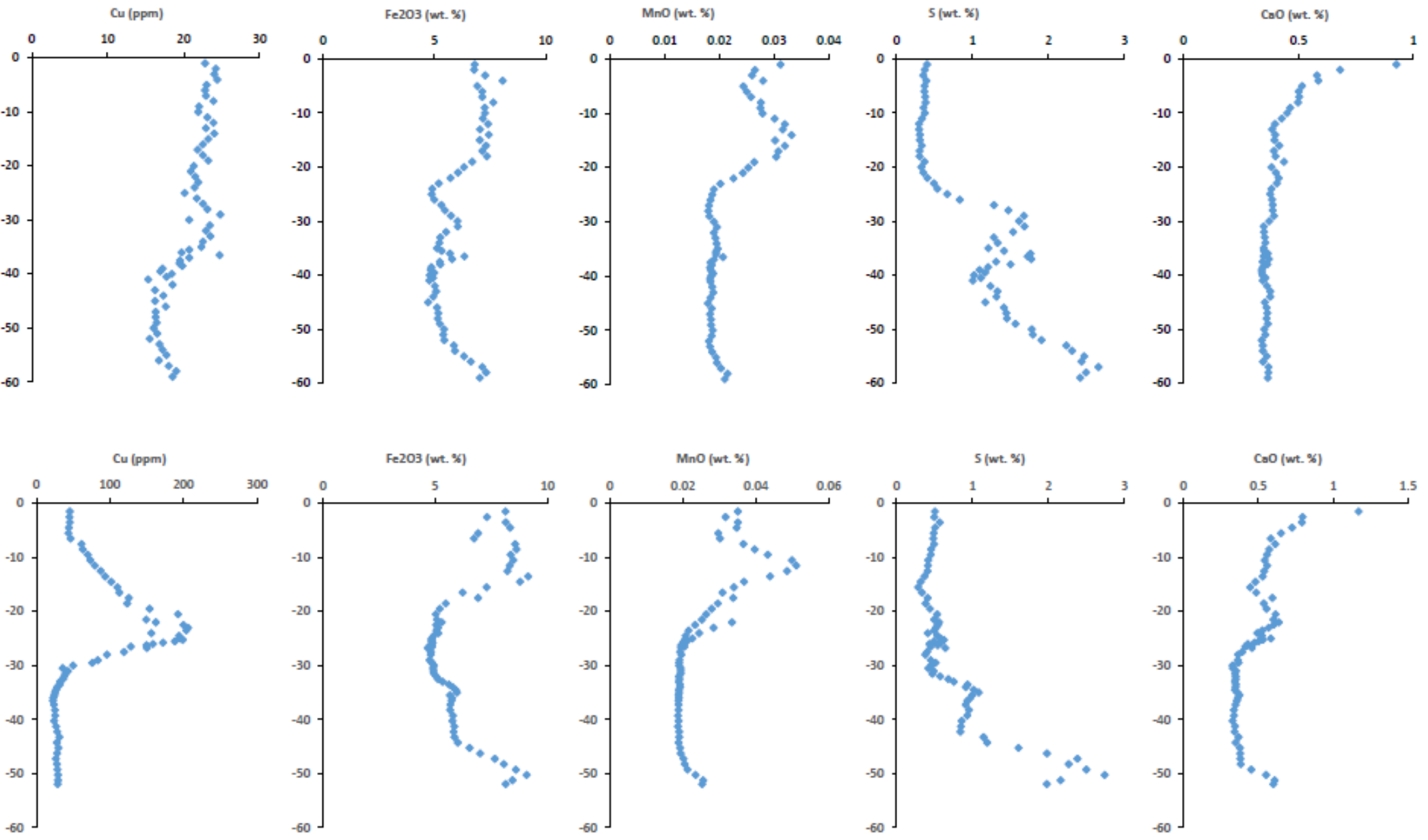

Figure 4: ${ }^{137} \mathrm{Cs}, \mathrm{Cu}, \mathrm{Fe}_{2} \mathrm{O}_{3}, \mathrm{MnO}, \mathrm{S}$, and $\mathrm{CaO}$ distribution with depth in Beaulieu (top) and Hythe (bottom) saltmarsh cores. 


\subsection{Geochemical associations of ECs, and effectiveness of the "estuarine filter".}

384 Consideration of bulk geochemical data for the redox-sensitive elements $\mathrm{Fe}, \mathrm{Mn}$ and $\mathrm{S}$ 385 (Figure 4) indicates that there is a relatively well-developed redox zonation in each core, with increases in solid phase sulphur at depth $(>25 \mathrm{~cm}$ depth, Beaulieu, greater than $30 \mathrm{~cm}$ depth, Hythe) reflecting the development of anoxic conditions in deeper sections of the marsh, resulting in sulphate reduction and precipitation of Fe sulphides. This redox zonation shows no apparent relationship with ECs distribution or with HAP:BPA ratio. Calcium distribution shows a decline with depth from a surface maximum value, as observed elsewhere (e.g. Spencer et al., 2003) due to decalcification, which occurs in oxic saltmarsh sediments in response to a lowering of $\mathrm{pH}$ resulting from nitrification and decomposition of organic matter.

The application of PCA highlighted clear differences in composition and contaminant geochemistry between the sites, with higher scores along axis 1 identified for the Hythe site and lower values for the Beaulieu site (Figure 5). Axis 1 however only accounted for $35.9 \%$ of the variation in the data, and axis 2 accounted for $18.2 \%$ of the variation, which shows (a) the multiparametric character of the data, and (b) the lack of clear association of ECs with any one defined component of the sediment. The main factors influencing axis 1 were: $\mathrm{K}_{2} \mathrm{O}$, $\mathrm{V}, \mathrm{Pb}, \mathrm{MgO}, \mathrm{TiO}_{2}, \mathrm{Ba}$, Sand, $\mathrm{Al}_{2} \mathrm{O}_{3}$, and $\mathrm{S}$, whereas the main factors influencing axis 2 were $\mathrm{Cl}$,

I, $\mathrm{Na}_{2} \mathrm{O}, \mathrm{P}_{2} \mathrm{O}_{5}, \mathrm{MnO}, \mathrm{CaO}, \mathrm{Cu}$, and $\mathrm{OC}$ (Figure 5). The principal factors that were found to differentiate the sites were those concerning sedimentary characteristics (e.g. granulometry, mineralogy, organic carbon, redox processes) with minor differences in the observed values of the organic pollutants between each studied estuary. This suggests that chemistry and contaminant binding is more complex than direct correlation (or direct 

interaction) of ECs with sedimentary particulate organic carbon - regardless of the 407 individual contaminant's functionality and hydrophobicity (Table 1, and Table S5). As 408 observed by other authors, this may at least partly be an effect of colloidal association and transport of these ECs (e.g. Kalmykova et al., 2013). Cluster analysis noted two main 410 groupings in each studied system. At Beaulieu, ECs are related with clay and silt (Figure 6a);

411 whereas at Hythe they are distributed across all sediment fractions such as sand, silt and 412 clay (Figure 6b). This suggests some degree of fine sediment association at Beaulieu, with 413 supply of ECs associated with fine suspended material that may have been sourced from 414 other areas in the estuary more impacted by industrial and leisure (e.g. boating) activity or 415 WWTWs.

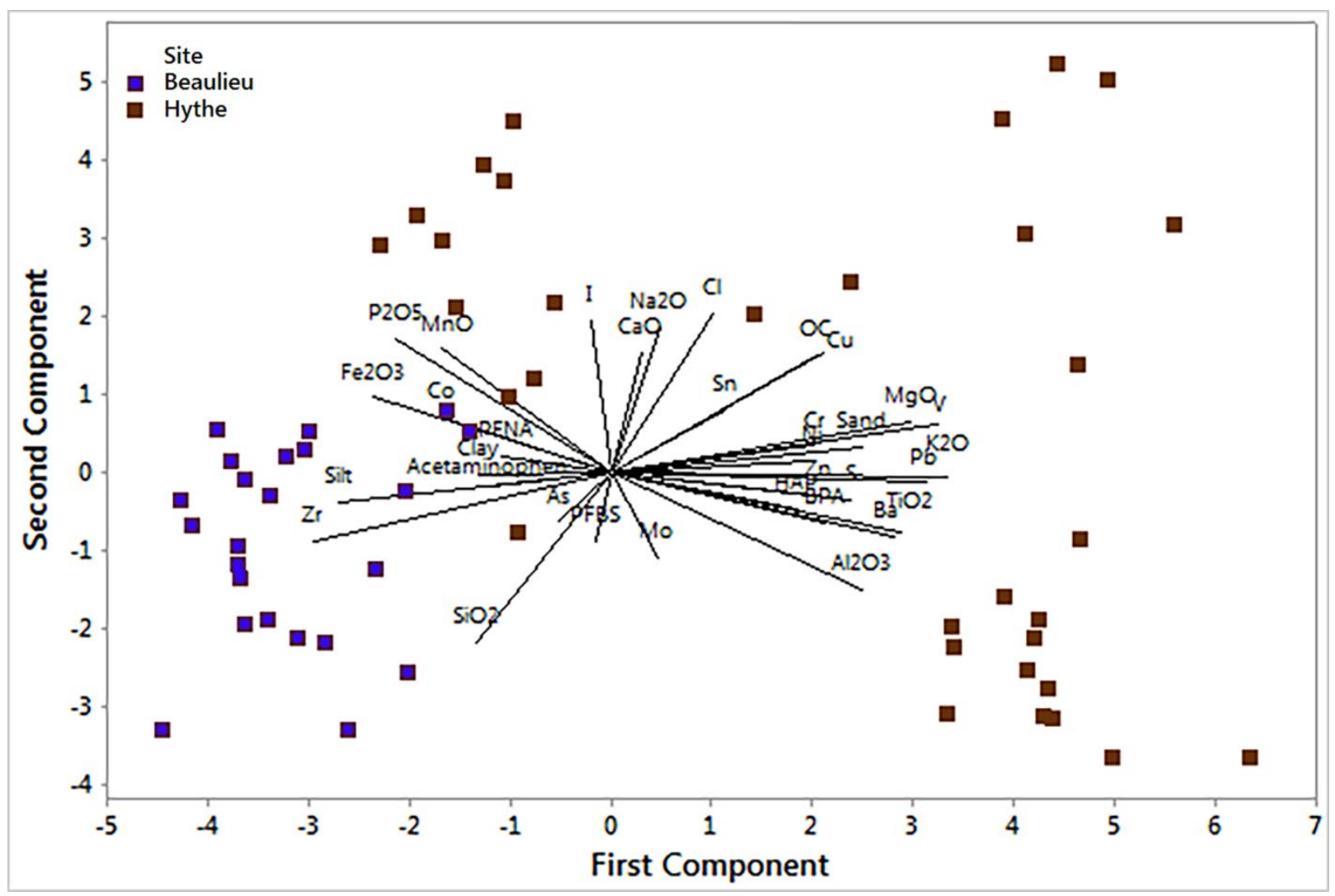


$418 \quad$ Figure 5: PCA ordination plot showing all subsamples from cores at Beaulieu and Hythe with 419 environmental vectors. 


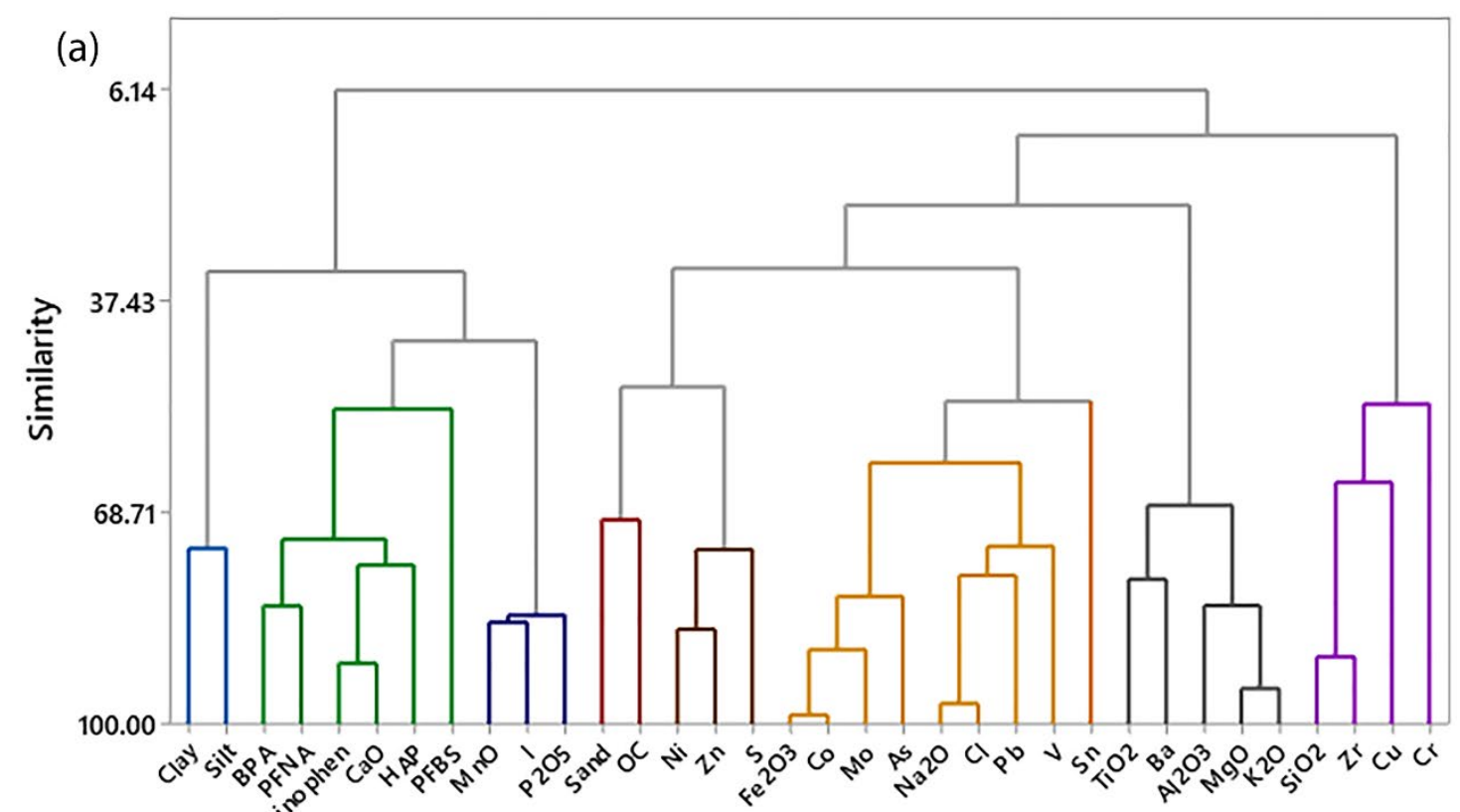

Variables

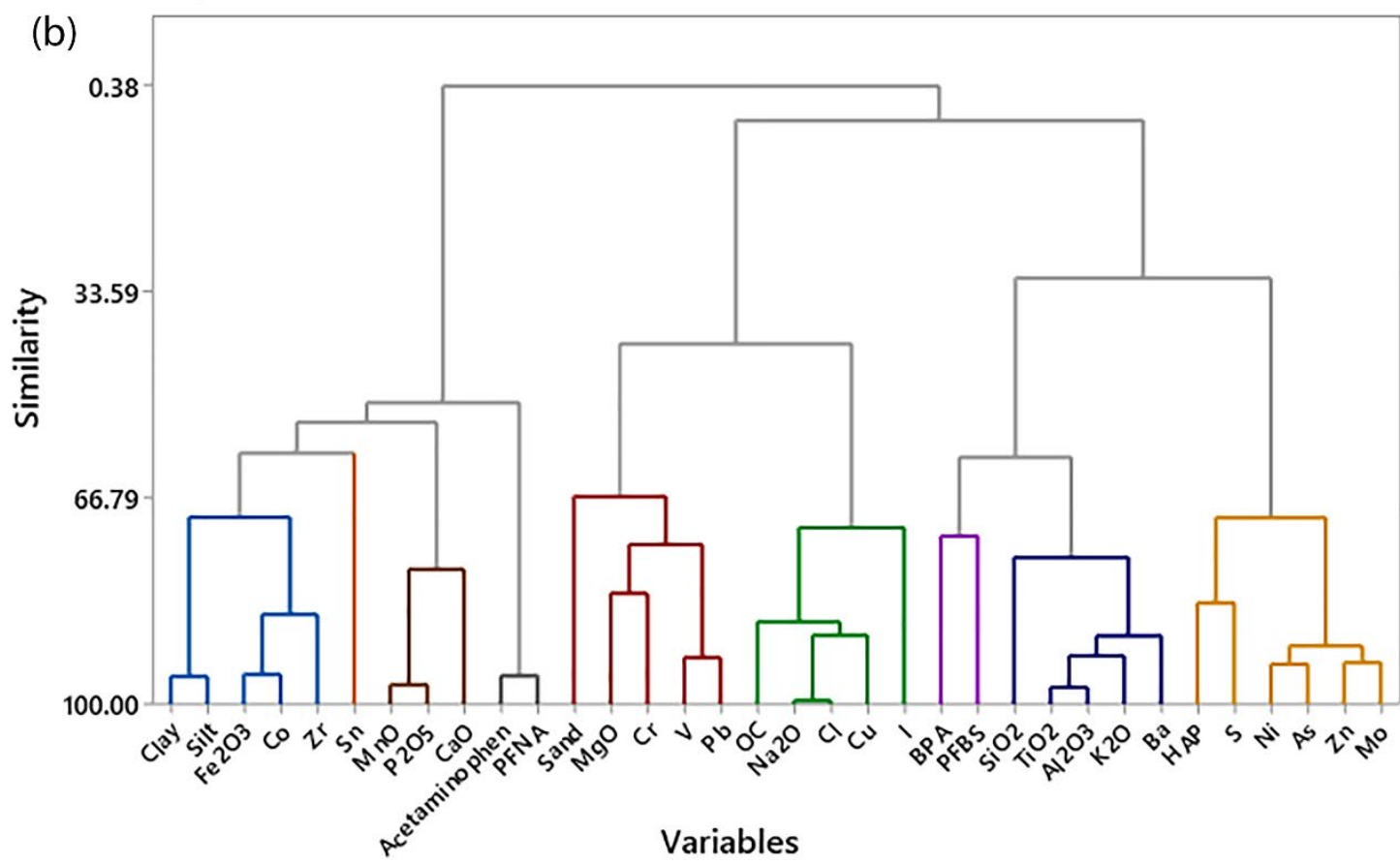

421

Figure 6: Tree diagram for the 34 core variables studied, derived from a cluster analysis

423 using the complete linkage 1-Pearson $r$ method. (a) shows data for Beaulieu and (b) shows

424 data for Hythe site. 
425 At the seawater pHs observed around the sampling sites (7-8.5), both ionised and non426 ionised forms of acetaminophen and the bisphenols will be present, although the neutral 427 species will be the most abundant. In contrast, the anionic form of the perfluoroalkyl acids will dominate (ITRC, 2020). Hence the perfluoroalkyl species will be expected to have a more amphiphilic character under these environmental conditions: with a fluorinated tail participating in van der Waals and hydrogen bonding interactions with organic matter and negatively charged carboxylic groups, with a capacity also to participate in hydrogen bonding and/or interact ionically with cations (e.g amino groups from organic matter or free metals). In addition, sorption (e.g. to organic carbon) generally increases with increasing perfluoroalkyl tail length, indicating that long-chain PFASs (for example, PFOA) would be expected to be more strongly sorbed than their shorter-chain counterparts (e.g. PFBS) (ITRC, 2020). Despite these likely differences in sediment binding potential, the data presented here show little apparent long-term sequestration in intertidal sediments for any of the seven ECs examined - while sediments are clearly labelled with these contaminants, the ECs are apparently relatively mobile in the marsh systems studied, and a contaminant chronology or record of temporal inputs is not retained in the sediment cores. Where subsurface maxima are present (most prominently here for BPA at the Hythe marsh) these most likely relate to local flushing or diffusive processes and cannot be clearly linked to likely input trends or changes in sediment geochemistry. Unlike radionuclides and heavy metals, which are effectively sequestered and buried for long periods (depending on longer term sediment accumulation and marsh erosion trends, e.g. Cundy and Croudace (2017)), the "estuarine filter" here, at least for these intertidal saltmarsh sediments, shows reduced potential to sequester the seven ECs examined and mediate their supply to coastal and shelf environments. 


\section{Conclusions}

- Seven, relatively water-soluble and environmentally mobile, ECs were examined and found to be present in the $\mathrm{ng} / \mathrm{g}$ range in both Hythe and Beaulieu saltmarsh sediments, with concentrations ranging from $0.12 \mathrm{ng} / \mathrm{g}$ (acetaminophen), through 0.2-5.3 ng/g (perfluoroalkyl compounds) to $7.9-16.5 \mathrm{ng} / \mathrm{g}$ (BPA, BPS and HAP).

- Broadly similar mean concentrations were found between the Hythe and Beaulieu sediment cores for all ECs examined, indicating a relative ubiquity of these ECs in estuarine waters on the central southern UK coast. The lack of clear enrichment in ECs in the heavily urbanised and industrialised Southampton Water (Hythe) system over those found in the non-urbanised Beaulieu estuary is most likely a consequence of ECs input from a range of catchment sources, rather than a single main or point source, and mixing of these inputs on the tidal circulation prior to deposition in the marsh systems.

- The ECs are apparently relatively mobile in the marsh systems studied, and where subsurface concentration maxima are present these most likely relate to local flushing or diffusive processes and cannot be clearly linked to likely input trends or changes in sediment geochemistry (including in sedimentary organic carbon content).

- Despite their likely differences in sediment binding potential (with reported Log Kow values ranging from $c a .0 .5$ to $>7$ ), the data presented here show little apparent long-term sequestration in intertidal sediments for any of the ECs assessed. Unlike radionuclides and heavy metals, which can be effectively sequestered and buried for 
long periods, the "estuarine filter" here, at least for these intertidal saltmarsh sediments, shows reduced potential to sequester the ECs examined and mediate their supply to coastal and shelf environments.

\section{SUPPORTING INFORMATION.}

Further information on background contamination and analyte recovery, and tables of quality parameters in the determination of ECs, mass spectrometry acquisition conditions, limits of detection and quantification for each studied EC analyte, uncertainties in the quantification of the study compounds, and correlation matrix including granulometry, organic carbon and organic pollutants for study sites.

\section{AUTHOR INFORMATION.}

\section{Corresponding Author}

* Corresponding author: Professor Andrew B. Cundy, School of Ocean and Earth Science, University of Southampton, National Oceanography Centre (Southampton), European Way, Southampton, SO14 3ZH, U.K. Email - A.Cundy@soton.ac.uk

\section{ACKNOWLEDGEMENTS.}

$\mathrm{OCH}$ is grateful to the Consejo Nacional de Ciencia y Tecnologia (CONACYT), Mexico for funding through the scholarship program (No 209683), and to the Universities of Southampton and Brighton for hosting the Fellowship under which this work was undertaken. RB acknowledges GCRF-UKRI funding received from Kingston University. 
494

495 NOTES.

496 The authors declare no competing financial interest. 
Ahrens, L.; Norström, K.; Viktor, T.; Cousins, A.P.; Josefsson, S. Stockholm Arlanda Airport as a source of per-and polyfluoroalkyl substances to water, sediment and fish. Chemosphere. 2015, 129, 33-38.

Anderson, R.H.; Long, G.C.; Porter, R.C.; Anderson, J.K. Occurrence of select perfluoroalkyl substances at US Air Force aqueous film-forming foam release sites other than fire-training areas: Field-validation of critical fate and transport properties. Chemosphere. 2016, 150, 678-685.

Arp, H. P.; Niederer, C.; Goss, K.-U. Predicting the partitioning behavior of various highly

507 fluorinated compounds. Environ. Sci. Technol. 2006, 40, 7298-7304.

CEFAS. Beaulieu River Sanitary Survey. Centre for Environment, Fisheries and Aquaculture

Science, Weymouth, Dorset, UK, 2015; https://www.cefas.co.uk/publications-data/foodsafety/sanitary-surveys/england-and-wales/.

511 Chen, L.; Hu, Ch.; Tsui, M.M.P.; Wang, T.; Peterson, D.R.; Shi, Q.; Lam, P.K.S.; Au, T.; Lam,

512 J.C.W.; Zhou, B. Multigenerational Disruption of the Thyroid Endocrine System in Marine Medaka after a Life-Cycle Exposure to Perfluorobutanesulfonate. Environ. Sci. Technol. 2018, 52, 4432-4439.

Costa F.; Lago, A.; Rocha, V.; Barros, O.; Costa, L.; Vipotnik, Z.; Silva, B; Tavares, T. A Review on Biological Processes for Pharmaceuticals Wastes Abatement-A Growing Threat to Modern Society. Environ. Sci. Technol. 2019, 53, 7185-7202. 
Craft, C.; Senega, E.; Broome, S. Loss on ignition and Kjeldahl digestion for estimating

520 Croudace I.W; Cundy A.B. A record of heavy metal and hydrocarbon pollution in recent sediments from Southampton Water, southern England: a geochemical and isotopic study, Environ. Sci. Technol. 1995, 29, 1288-1296.

524 Tritiated Organic Compounds in an Estuarine Sedimentary Environment. Environ. Sci. Technol. 2012, 46, 11, 5704-5712.

Cundy, A.B.; Croudace, I.W. Sediment Accretion and Recent Sea-level Rise in the Solent,

527 Southern England: Inferences from Radiometric and Geochemical Studies. Estuar. Coast.

Cundy, A.B.; Croudace, I.W.; Thomson, J.; Lewis, J.T. Reliability of Salt Marshes as Southern England. Environ. Sci. Technol. 1997, 31, 1093-1101.

Cundy A.B.; Croudace, I.W. The fate of contaminants and stable Pb isotopes in a changing estuarine environment: 20 years on. Environ. Sci. Technol. 2017, 51, 9488-9497. isolated from polluted soil, Guangdong, China. BMC microbiology. 2020, 20, 11. 
Gaston L.; Lapworth, D.J.; Stuart, M.; Arnscheidt, J. Prioritization Approaches for Substances

538 of Emerging Concern in Groundwater: A Critical Review. Environ. Sci. Technol. 2019, 53,

$539 \quad 6107-6122$.

540 Goss, K-U. The pKa values of PFOA and other highly fluorinated carboxylic acids. Environ. Sci.

541 Technol. 2008, 42, 456-458.

542 Hong, S.; Shin, K. Alkylphenols in the core sediment of waste dumpsite in the East Sea (Sea

543 of Japan), Korea. Mar. Pollut. Bull. 2009, 58, 1566-1587.

544 Howard, P.H.; Meylan, W.M. (Eds.). Handbook of Physical Properties of Organic Chemicals,

545 Part 1. Lewis Publishers, CRC Press, Baton Rouge, 1997, pp.2112.

546 Hydes, D. Nutrients in the Solent: Solent Science- A Review. Collins, M.B., Ansell, K., Eds;

547 Progress in Marine Science; Elsevier Science; 2000; pp. 135-148.

$548 \mathrm{ICH}, 2005$. International Conference on Harmonisation, Harmonised Tripartite Guideline 549 Validation of Analytical Procedures: Text and Methodology Q2(R1) Interstate Technology Regulatory Council (ITRC). Technical resource for addressing environmental releases of Per- and Polyfluoroalkyl substances (PFAS). ITRC, Washington DC, USA, 2020; https://pfas-1.itrcweb.org/\# (accessed July 2020)

554 (accessed July 2020). hydrocarbons, alkylphenols, bisphenol A and phthalates in landfill leachates and 
Kim, S.; Lee, S.; Kim, Ch.; Liu, X.; Seo, J.; Jung, H.; Ji, K.; Hong, S.; Park, J.; Khim, J.S.; Yoon, S.;

559 Lee, W.; Park, J.; Choi, K. In vitro and in vivo toxicities of sediment and surface water in an area near a major steel industry of Korea: Endocrine disruption, reproduction on survival effects combined with instrumental analysis. Sci. Total Environ. 2014, 470-471, 1509-1516. 1211. migration of steroidal estrogens through river bed sediments. Environ. Sci. Technol. 2007, 41, $4299-4304$.

Little, D.I.; Howells, S.E.; Smith, J.; Mangini, A. Time Sequence and Fate of Contaminants in Core Sediments of Southampton Water. Technical Report, FSC/OPRU/16/87, Field Studies Council, Pembroke, UK. 1988, DOI: 10.13140/RG.2.2.22701.64482.

Lubecki, L.; Kowalewska, G. Plastic-derived contaminants in sediments from the coastal zone of the southern Baltic Sea. Mar. Pollut. Bull. 2019, 146, 255-262.

574 Mourier, B.; Labadie, P.; Desmet, M.; Grosbois, C.; Raux, J.; Debret, M.; Copard, Y.; Pardon, P.; Budzinski, H.; Babut, M. Combined Spatial and Retrospective Analysis of Fluoroalkyl

576 Chemicals in Fluvial Sediments Reveal Changes in Levels and Patterns over the Last 40 Years.

577 Environ. Pollut. 2019, 253, 1117-1125. 
Munoz, G.; Budzinski, H.; Labadie, P. Influence of Environmental Factors on the Fate of Legacy and Emerging Per- and Polyfluoroalkyl Substances along the Salinity/Turbidity Gradient of a Macrotidal Estuary. Environ. Sci. Technol. 2017, 51, 21, 12347-12357

Munro, K.; Martins, C.P.B.; Loewenthal, M.; Comber, S.; Cowan, D.A.; Pereira, L.; Barron, L.P. Evaluation of combined sewer overflow impacts on short-term pharmaceutical and illicit drug occurrence in a heavily urbanised tidal river catchment (London, UK). Sci. Total Environ. $2019,657,1099-1111$.

Osenbrück, K.; Gläser, H.R.; Knöller, K.; Weise, S.M.; Möder, M.; Wennrich, R.; Schirmer, M.; Reinstorf, F.; Busch, W.; Strauch, G. Sources and transport of selected organic micropollutants in urban groundwater underlying the city of Halle (Saale), Germany. Wat. Res. 2007, 41, 3259-3270.

Pan, Ch., G.; Wang, Y., H.; Yu, K., F.; Zhang, W.; Zhang, J.; Guo, J. Occurrence and distribution of perfluoroalkyl substances in surface riverine and coastal sediments from the Beibu Gulf, south China. Mar. Pollut. Bull. 2020, 150, 110706.

Peng, X.; Wang, Z.; Mai, B.; Chen, F.; Chen, S.; Tan, J.; Yu, Y.; Tang, C.; Li, K.; Zhang, G.; Yang, C. Temporal trends of nonylphenol and bisphenol A contamination in the Pearl River Estuary and the adjacent South China Sea recorded by dated sedimentary cores. Sci. Total Environ. $2007,384,393-400$.

Petrie, B.; Barden, R.; Kasprzyk-Hordern, B. A review on emerging contaminants in wastewaters and the environment: current knowledge, understudied areas and recommendations for future monitoring. Water Res. 2015, 72, 3-27. 
599

600

601

602

603

604

605

606

607

608

609

610

Proctor, K.; Petrie, B.; Lopardo, L.; Camacho Munoz, D.; Rice, J.; Barden, R.; Arnot, T.;

Kasprzyk-Hordern, B. Micropollutant fluxes in urban environment - A catchment

perspective. J. Haz. Mat. 2020, 401, 123745.

Quaresma, V.S.; Bastos A.C.; Amos, C.L. Sedimentary processes over an intertidal flat: A field investigation at Hythe flats, Southampton Water (UK). Mar. Geol. 2007, 241, 117-136.

Richardson, S.; Ternes, T.A. Water analysis: emerging contaminants and current Issues. Anal. Chem. 2018, 90, 398-428.

Schaefer, A.; Booth, B.; Lubick, N; Betts, K.S. Plastic pipes could contaminate water. Environ. Sci. Technol. 2006, 40, 23, 7108-7114 (news).

Senthilkumar, K.; Ohi, E.; Sajwan, K.; Takasuga, T.; Kannan, K. Perfluorinated compounds in river water, river sediment, market fish, and wildlife samples from Japan. B. Environ. Contam. Tox. 2007, 79, 427-431.

Smital, T. Acute and Chronic Effects of Emerging Contaminants. In: Barceló D., Petrovic M. (eds) Emerging Contaminants from Industrial and Municipal Waste. The Handbook of Environmental Chemistry, vol 5S/1. 2008, pp 105-142. Springer, Berlin, Heidelberg. https://doi.org/10.1007/698_5_105.

Southampton City Council, 2019. Southampton Strategic Assessment. https://data.southampton.gov.uk/ (accessed July 2020).

Spencer K.; Cundy, A.B.; Croudace, I.W. Heavy metal distribution and early-diagenesis in salt marsh sediments from the Medway estuary, Kent, U.K. Estuar. Coast. Shelf S. 2003, 57, 43-

54. 
621 of emerging contaminants in the estuarine receiving environment around Auckland, New

622 Zealand, Sci. Total Environ. 2014, 468-469, 202-210.

623 Thiebault, T.; Chassiot, L; Fougere, L.; Destandau, E.; Simonneau, A.; Van Beek, P.; Souhaut, 624 M.; Chapron, E. Record of pharmaceutical products in river sediments: A powerful tool to 625 assess the environmental impact of urban management? Anthropocene. 2017, 18, 47-56

626 Thomas, J.K.; Birceanu, O.; Sadoul, B; Vijayan, M.M. Bisphenol A in Eggs Impairs the Long627 Term Stress Performance of Rainbow Trout in Two Generations. Environ. Sci. Technol. 2018, $628 \quad 52,7951-7961$.

629 Thomson, J.; Dyer, F.M.; Croudace, I.W. Records of radionuclide deposition in two salt 630 marshes in the United Kingdom with contrasting redox and accumulation conditions.

631 Geochim. Cosmochim. Ac. 2002, 66 (6), 1011-1023.

632 Turner, A. Salting out of chemicals in estuaries: implications for contaminant partitioning 633 and modelling. Sci. Total Environ. 2003, 314-316, 599- 612.

Velegrakis, A.F.; Michel, D.; Collins, M.B.; Lafite, R.; Oikononow, E.K.; Dupont, J.P.; Huault, M.F.; Lecouturier M.; Salomon J.C.; Bishop, C. Sources, sinks and resuspension of suspended particulate matter in eastern English Channel. Cont. Shelf Res. 1999, 19, 1933-1957. using combined chemical and biological tools. Environ. Pollut. 2011, 159, 148-156. 
640

641

642

643

644

645

646

647

648

649

650

651

652

653

654

655

656

657

658

659

660

661

Wang, X.; Yu, J.; Wang, Y.; Wang, L. Mechanism-based quantitative structure-activity relationships for the inhibition of substituted phenols on germination rate of Cucumis sativus. Chemosphere 2002, 46, 241-250.

White, N.D.; Bathis, L.; Kannan, K.; De Silva, A.; Wu, Q.; French, K.M.; Dougomah, J.; Spencer, $\mathrm{CH}$.; Fair, P. Elevated levels of perfluoroalkyl substances in estuarine sediments of Charleston, S.C. Sci. Total Environ. 2015, 521-522, 79-89.

Wilkinson, J.L.; Hooda, P.S.; Barker, J.; Barton, S.; Swinden, J. Ecotoxic pharmaceuticals, personal care products, and other emerging contaminants: a review of environmental, receptor-mediated, developmental, and epigenetic toxicity with discussion of proposed toxicity to humans. Crit. Rev. Environ. Sci. Technol. 2015, 46 (4), 336-381.

Wilkinson J.L.; Swinden, J.; Hood, P.; Barker, J.; Bartons, S. Markers of anthropogenic contamination: A validated method for quantification of pharmaceuticals, illicit drug metabolites, perfluorinated compounds, and and plasticisers in sewage treatment effluent and rain runoff. Chemosphere. 2016, 159, 638-646.

Wilkinson, J.L.; Hooda, P.S.; Swinden, J.; Barker, J.; Barton, S.; Spatial (bio) accumulation of pharmaceuticals, illicit drugs, plasticisers, perfluorinated compounds and metabolites in river sediment, aquatic plants and benthic organisms. Environ. Pollut. 2018, 234, 864-875.

Xiao, F.; Simcik, M.F.; Gulliver, J.S. Perfluoroalkyl acids in urban stormwater runoff: influence of land use. Water Res. 2012, 46(20), 6601-6608.

Yan, H.; Zhang, C.; Zhou, Q.; Yang, S. Occurrence of perfluorinated alkyl substances in sediment from estuarine and coastal areas of the East China Sea. Environ. Sci. Pollut. R. 2015, 22(3), 1662-1669. 
662 Zhang, W., Yin, K. and Chen, L. Bacteria-mediated bisphenol A degradation. Applied 663 microbiology and biotechnology, 2013, 97, 5681-5689.

664 Zhao, Y.; Yang, Sh.; Li, H.; Wang, D. Adsorption behaviors of acetaminophen onto sediment 665 in the Weihe River, Shaanxi, China. Int. J. Sediment. Res. 2015, 30, 263-271.

666 Zushi, Y; Masunaga, S. Identifying the nonpoint source of perfluorinated compounds using a 667 geographic information system based approach. Environ. Toxicol. Chem. 2009, 28(4), 691668700. 


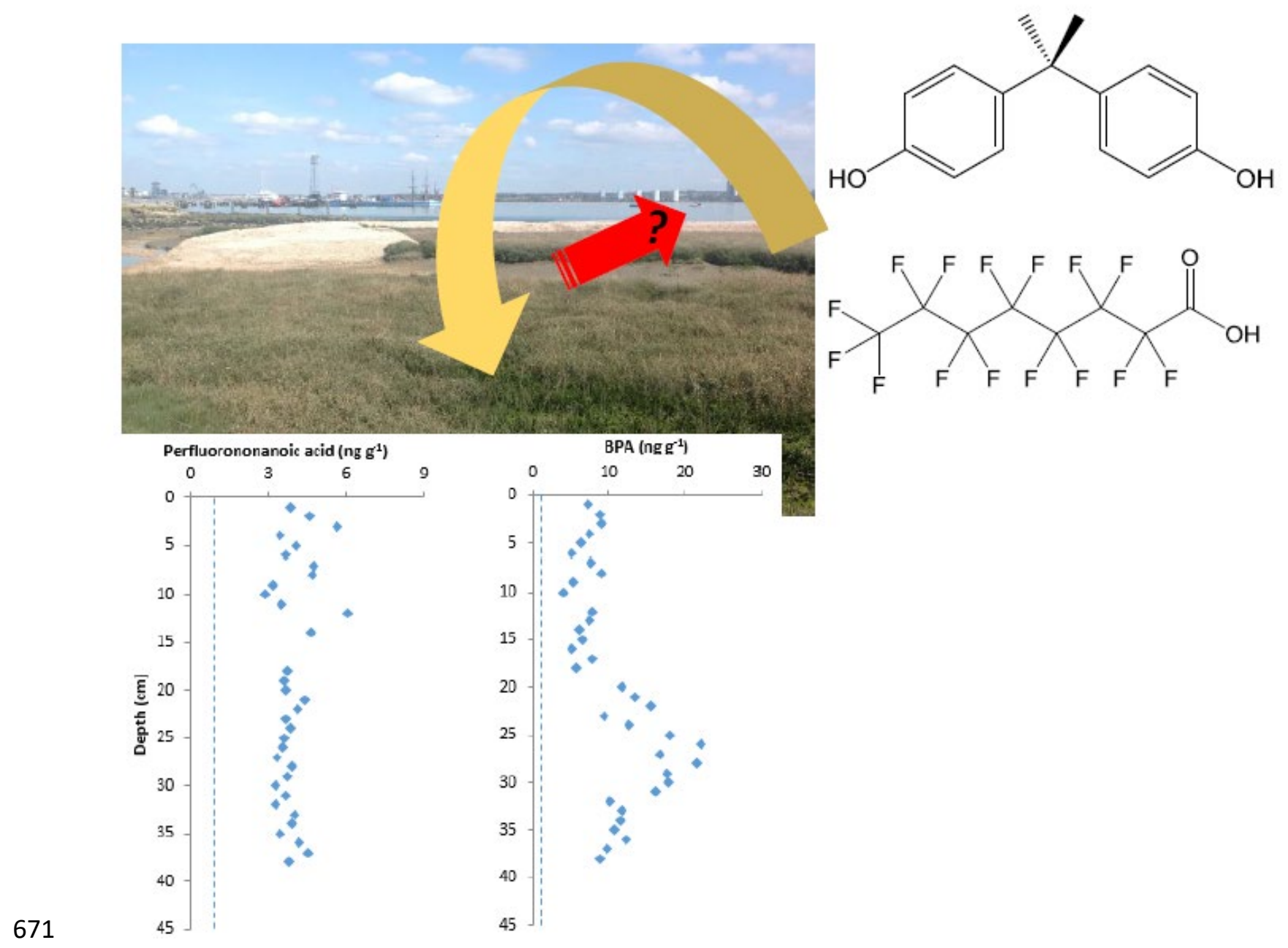

